Proceedings of the New Zealand Grassland Association 46: $217-220$ (1985)

\title{
WHITE CLOVER CULTIVAR EVALUATION FOR THE WAIKATO: ESTABLISHMENT PHASE
}

C.P. WEST and K.W. STEELE

Ruakura Soil and Plant Research Station, MAF, Hamilton

\begin{abstract}
Nine white clover (Trifolium repens L.) cultivars were established in a field trial near Hamilton to assess their adaptability to high fertility, intensively managed dairy pastures in the Waikato. The data presented are for the establishment phase of a three-year trial on Horotiu sandy loam in which cultivars will be evaluated for their persistence, competitiveness and $\mathrm{N}_{2}$-fixing ability in the presence of perennial ryegrass (Lolium perenne L.) and application of $N$ fertiliser. Three entries from New Zealand were "Grasslands Huia", "Grasslands Pitau" and the Grasslands selection G18. Six cultivars from Europe were Aran, Blanca, Donna, Menna, Nesta and Sabeda. The cultivars represent a range of leaf sizes from medium-small to large.

Aran and G18 (large leaved) generally developed stands with fewer thicker stolons than the other cultivars. Visual ratings of clover stand vigour during January to March 1983, . indier !e d that Gis had the greatest rate of estabilishment and ground cover despite its low stolon density. Perennial ryegrass seedling establishment was the least vigorous in G18 and Aran, and the most vigorous in Sabeda swards. Clover dry matter yields were generally highest for G18, Aran, Huia, Pitau and Donna, and lowest for Sabeda, Nesta and Menna. G18, Huia, Pitau, Blanca and Donna maintained a higher clover content in the sward during the weedy establishment phase than the other cultivars.
\end{abstract}

Keywords: Trifolium repens L., pasture establishment, white clover establishment.

\section{INTRODUCTION}

The application of nitrogen $(\mathrm{N})$ fertiliser to white clover (Trifolium repens L.)-perennial ryegrass (Lolium perenne L.) pastures to boost out-of-season production has been gaining in practice in New Zealand. Fertiliser $N$ usually inhibits symbiotic $\quad \mathrm{N}_{2}$-fixation in clover without substantially affecting its growth (Allos \& Bartholomew, 1959), but greatly stimulates grass growth, conferring upon the grass a competitive advantage over the clover for environmental resources (Donald, 1963). After the grass response to a single application of $\mathrm{N}$ fertiliser wears off, a depression in herbage production is often observed, which is attributed to a decline in clover growth (Steele et al., 1981). White clover cultivars have been developed in Europe that have shown to be more competitive with the grass and maintain a higher percentage in a N-fertillsed sward than older, commonly grown cultivars (Wilman \& Asiegbu, 1982). Some recently developed cultivars in New Zealand have not been adequately tested for their competitiveness under $\mathrm{N}$-fertilised regimes.

A field trial was initiated near Hamilton to assess the persistence, competitiveness, and $\mathrm{N}_{2} \cdot \mathrm{fixing}$ abilities of nine white clover cultivars for use in high fertility, intensively managed dairy pastures in the Waikato. The cultivars included six from Europe and three from New Zealand, and exhibited a range of leaf size from medium-small to large. This paper presents data from the establishment phase of the trial to demonstrate whether the overseas cultivars establish similarly to New Zealand cultivars in the Waikato environment. 


\section{MATERIALS AND METHODS}

The trial was located adjacent to Hamilton airport on a Horotiu sandy loam soil. The site was sprayed with glyphosate on 26.4 .82 and with ethofumesate on 24.582 to kill the existing sward of perennial ryegrass and white clover. The site was ploughed on 16.8.82, limed to $\mathrm{pH} 6.1$, topdressed with $1250 \mathrm{~kg} / \mathrm{ha}$ of $15 \%$ potassic superphosphate, then rotary hoed and harrowed twice.

The trial was arranged in a split-plot, randomised complete block design, with three $\mathrm{N}$ fertiliser treatments as main plots and nine clover cultivars as subplots. The cultivars were (in descending order of leaf size, followed by country) Aran (Ireland), G18 (NZ), Sabeda (UK), Blanca (Belgium), Donna (UK), Nesta (UK), "Grasslands Pitau" (NZ), Menna (UK), and "Grasslands Huia" (NZ). There were five replications and each subplot was $6 \mathrm{~m} \times 2 \mathrm{~m}$. Clover seed of the cultivars was broadcast by hand on 27.9.82, at rates delivering the same number of viable seed as in $5 \mathrm{~kg} / \mathrm{ha}$ of Huia. The seed was scarified before sowing, but was not inoculated with Rhizobium. The plots were raked lightly after sowing.six months later "Ellett" perennial ryegrass was drilled across all plots. The $\mathrm{N}$ fertiliser treatments did not begin until 11.6.83.

The establishment period extended from the time of clover sowing to the end of April 1983, at which point the undersown perennial ryegrass was in the three-leaf seedling stage. During this period, measurements of clover DM yield and botanical composition were done only on the main plots which were to become the control plots unfertilised with $\mathrm{N}$. Counts of white clover growing points and visual ratings of stand vigour were made on all three main plots in each block, effectively providing 15 replications per cultivar.

The plots were mown on 11.11 .82 to remove excessive weed growth. The trial area was sprayed with bentazone at $1 \mathrm{~L} / \mathrm{ha}$ and 2,4-DB at $1.5 \mathrm{~kg} / \mathrm{ha}$ in November 1982 for broadleaf weed control. The plots were again mown off on 6.12 .82 , then sprayed with 2,4-DB again. Fusilade was applied at $2 \mathrm{~L} / \mathrm{ha}$ in December 1982 to control grasses, and dock weeds were sprayed with $1.5 \mathrm{~kg} / \mathrm{ha}$ of asulam in February 1983. By late March 1983, weed populations were very low. To control nematodes, oxamyl was sprayed at $5 \mathrm{~kg} / \mathrm{ha}$ in February and March 1983. The trial area was irrigated at $3-4$ weekly intervals from December 1982 to March 1983.

Growing point densities were estimated in 21.10.82, 15.12 .82 and 29.3.83 using a $20 \mathrm{~cm} \times 20 \mathrm{~cm}$ quadrat in six random locations in each plot. Growing points consisted of apical meristems actively producing new leaves and comprised the main meristem of the original seedling and terminal growing tips of stolons having at least one internode.

From January, harvests were made 4 weekly by mowing two $6 \mathrm{~m} \times 0.45 \mathrm{~m}$ strips in each plot. Subsamples were taken for dry matter (DM) determinations. Further samples were clipped for separation into weed and clover components after which all herbage was trimmed off. Immediately before harvest (except on 21.2.83) a visual rating of clover stand vigour was made based on stand density and stage of plant development. A similar rating of perennial ryegrass seedlings was done on 29.4.83. Cultivar means were tested by analysis of variance.

\section{RESULTS \& DISCUSSION}

The white clover cultivars exhibited similar ranges of growing point densities on the first two counting dates (Table 1). At count 1 (21.10.82) the seedlings were not stoloniferous; however, by count 2 (15.12.82), the plants had one to three stolons. Numbers of individual, entire clover plants on 15.21.82 (not shown) had declined since the first count, but this decline in main growing points was essentially compensated by stolon development. Aran had the lowest growing point density on all dates. G18 and Aran were large-leaved cultivars that generally produced fewer, thicker stolons than the other cultivars. 
Tabl e 1: CONNTS OF WH TE CLOVER GRONNG PO NTS PER $\mathbf{M}^{2}$.

\begin{tabular}{lccc}
\hline Cultivar & $\mathbf{2 0 . 1 0 . 8 2 ^ { 1 }}$ & $\mathbf{1 5 . 1 2 . 8 2 ^ { 1 }}$ & $\mathbf{2 9 . 3 . 8 3 ^ { 2 }}$ \\
\hline Hui a & $\mathbf{4 8 2}$ & $\mathbf{4 2 2}$ & 1552 \\
Pi tau & $\mathbf{4 2 5}$ & 408 & 1583 \\
G18 & 372 & 382 & 1214 \\
Aran & 312 & 289 & $\mathbf{a 7 2}$ \\
Bl anca & 518 & 466 & 1453 \\
Donna & 395 & 357 & 1615 \\
Menna & 395 & 421 & 1583 \\
Nesta & 420 & 339 & 1335 \\
Sabeda & 370 & 379 & 1344 \\
SED & 23 & 22 & 195 \\
\hline
\end{tabular}

Means of 15 repl i cations

2 Means of 5 repl i cations

Tabl E 2: V SUAL RATI NG OF STAND V GOUR, MEANS OF 15 REPLI CATI ONS ( 1 = LEAST V GOUROUS, $5=$ MDST V GOROUS).

\begin{tabular}{lcccc}
\hline & \multicolumn{3}{c}{ Clover } & Grass \\
\cline { 2 - 4 } \cline { 2 - 4 } Cultivar & 20.1 .83 & 23.3 .83 & 29.4 .83 & 29.4 .83 \\
\hline Hui a & 3.7 & 3.7 & 3.9 & 2.3 \\
Pi tau & 3.5 & 3.4 & 4.1 & 2.1 \\
G18 & 3.9 & 3.6 & 4.2 & 1.4 \\
Aran & 3.5 & 3.1 & 3.8 & 1.7 \\
Bl anca & 3.6 & 3.2 & 3.8 & 2.3 \\
Donna & 3.6 & 3.3 & 3.9 & 2.1 \\
Menna & 3.5 & 3.5 & 4.0 & 2.2 \\
Nesta & 3.4 & 2.9 & 4.0 & 2.5 \\
Sabeda & 2.7 & 2.7 & 3.4 & 2.7 \\
SED & 0.2 & 0.2 & NS & 0.4 \\
\hline
\end{tabular}

NS Non si gni fi cant

Tabl E 3: CLOVER DRY MATTER YI ELD, KG HA, MEANS OF 5 REPLI CATI ONS

\begin{tabular}{lcccc}
\hline Cultivar & 20.1 .83 & 21.2 .83 & 23.3 .83 & 29.4 .83 \\
\hline Hui a & 764 & 1108 & 904 & 1009 \\
Pi tau & $a 51$ & 965 & 962 & 1046 \\
G18 & 917 & 1210 & 1063 & 1157 \\
Aran & 993 & 1077 & a45 & 1041 \\
Bl anca & 1073 & 1140 & 597 & 1001 \\
Donna & 971 & 1092 & 940 & 1074 \\
Menna & 863 & 937 & 669 & 927 \\
Nesta & 749 & 898 & 545 & a42 \\
Sabeda & 624 & 905 & 514 & al 4 \\
SED & NS & NS & 154 & 92 \\
\hline
\end{tabular}

NS Non si gni fi cant 
Visual ratings of stand vigour (Table 2) indicated that the New Zealand clovers "Grasslands Huia" (medium-small leaved) and G18 tended to develop the greatest ground cover, whereas for Sabeda (medium-large leaved), establishment was slow and uneven. By January 1983, the larger leaved cultivars were easily discernible and volunteer clover infestation appeared negligible. The ratings of grass stand vigour on 29.4.83 demonstrated that grass establishment was inhibited by the presence of the large-leaved cultivars G18 and Aran, compared with the other, small leaved cultivars.

Dry matter yield of the clover cultivars was not significantly different in the first two harvests (Table 3). In subsequent harvests, clover yields tended to be highest with G18, "Grasslands Huia", "Grasslands Pitau", Aran and Donna; the lowest with Sabeda, Nesta and Menna. The latter cultivars also tended to have the lowest clover composition in the herbage (Table 4).

Table 4: PERCENTAGE CLOVER COMPOSITION OF HERBAGE DRY MATTER, MEANS OF 5 REPLICATIONS. (THE BALANCE OF THE HERBAGE CONSISTED MAINLY OF ANNUAL BROADLEAF WEEDS).

\begin{tabular}{lcccc}
\hline Cultivar & 20.1 .83 & 21.2 .83 & 23.3 .83 & 29.4 .83 \\
\hline Huia & 38.6 & 77.3 & 81.8 & 82.0 \\
Pitau & 39.1 & 67.6 & 75.0 & 81.0 \\
G18 & 43.8 & 82.3 & 83.9 & 86.9 \\
Aran & 42.1 & 71.7 & 76.1 & 75.3 \\
Blanca & 46.8 & 81.9 & 67.2 & 76.3 \\
Donna & 34.9 & 78.0 & 79.5 & 79.8 \\
Menna & 39.4 & 71.9 & 62.0 & 76.0 \\
Nesta & 33.2 & 70.0 & 63.8 & 68.0 \\
Sabeda & 30.7 & 62.2 & 55.8 & 65.2 \\
SED & NS & NS & 7.3 & 5.9 \\
\hline
\end{tabular}

NS Non significant

Stand vigour ratings and clover DM yield were considered as useful indices of stand establishment and development. The New Zealand entries did not differ in vigour and yield among themselves, but, G18 means tended to be highest. The nonNew Zealand cultivars generally established as well as the New Zealand entries with the exceptions of Nesta and Sabeda. Growing point density appeared to be a cultivar trait that was independent of degree of stand establishment.

\section{REFERENCES}

Allos, H.F.; Bartholomew, W.V. 1959. Soil Sci. 87: 61-87.

Donald, CM. 1963. Adv. Agron. 15: I-118.

Steele, K.W.; O'Connor, M.B.; Ledgard, S.F. 1981. Proc. Ruakura Fmrs' Conf. pp 53-56. Wilman, D.; Asiegbu, J.E. 1982. Grass Forage Sci. 37: I-13. 